\title{
Build It, Buy It, or Both? Rethinking the Sourcing of Advertising Services
}

\author{
Alvin J. Silk ${ }^{1} \&$ Marta M. Stiglin ${ }^{2}$ \\ ${ }^{1}$ Lincoln Filene Professor Emeritus, Harvard Business School, USA \\ ${ }^{2}$ Principal, Stiglin Consulting and Member, Board of Directors, In-House Agency Forum (IHAF), USA \\ Correspondence: Marta M. Stiglin, Post Office Box 823, Andover, MA, 01810, United States. Tel: \\ 1-978-609-7825. E-mail: marta@stiglin.com or Alvin J. Silk, Harvard Business School, Soldiers Field Road, \\ Boston, MA 02163, United States. Tel: 1-617-495-6036. E-mail: asilk@hbs.edu
}

Received: December 8, 2015 Accepted: December 23, 2015 Online Published: January 28, 2016

doi:10.5539/ijms.v8n1p1 URL: http://dx.doi.org/10.5539/ijms.v8n1p1

\begin{abstract}
This paper provides an update on the current state of in-house agencies. Whereas traditional consideration of internalizing advertising services was framed as a binary choice of build or buy, today's advertisers frequently pursue hybrid policies of build and buy to procure the customized bundle required to develop, produce, and implement relevant, resonant promotional campaigns. Increasing numbers of advertisers are discovering that the demand for advertising and marketing services is best served through the coordination and integration of resources from both inside and outside the company, rather than assuming that these options are mutually exclusive. A review of advertising industry history reveals why internal agencies have long operated in the shadows of their external counterparts and how the former organization form has evolved over time. The core competencies underlying the contemporary in-house agency model are analyzed and the competitive position that in-house agencies presently occupy in relation to external providers is assessed. Two case examples of successful internal/external agency collaboration are presented. Finally, recommendations are offered for advertisers seeking to bring their internal and external agency resources together and arrive at a more-collaborative operating model for advertising services.
\end{abstract}

Keywords: advertising, agency, ana, boeing, client, creative, ihaf, in-house, internal, leadership, management, marketing, organizational, performance, process, prudential, silk, strategy, stiglin

\section{Introduction}

A little-known conflict has been brewing within the advertising community for decades - tension over the coexistence of internal and external advertising agencies. Until recently, this quiet unease was placated by the contestable belief that in-house agencies were hobbled in their ability to attract and retain top talent and thereby disadvantaged in developing the capabilities necessary to deliver high-quality advertising services.

An in-house agency is best defined as an advertising organization that is owned and operated by the corporation it serves. Its mission is to provide advertising services in support of its parent company's business objectives for the benefit of a shared bottom line. External agencies perform a similar function, though serving the needs of multiple client companies for the benefit and profitability of their own. In comparison to external agencies, the in-house model has long been regarded as a marginal organizational form, operating on the fringes of the advertising ecosystem. Their position was presumed to be one of executing tactical programs and projects that required little strategic or creative prowess. Conventional wisdom held that more widely visible, highly valued strategic and creative work was properly the domain of the "professionals" employed by external ad agencies.

Only recently has the industry begun to acknowledge that internal agencies are capable of performing on par with external providers. This increased recognition is due, in large part, to a 2013 survey conducted by the Association of National Advertisers (ANA) that found that the majority (58\%) of its responding membership employed internal agencies - up from $42 \%$ in 2008 , and considerably above the $11 \%$ penetration reported nearly 40 years ago (ANA, 1976). Interestingly, the 2013 ANA study operationally defined an in-house agency as a "department, group, or person that has responsibilities typically performed by an external advertising or other marcomm [marketing communications] agency" (ANA, 2013, p. 5). 
These survey results came as a surprise to many industry insiders, inasmuch as the ANA's membership roster includes virtually all (565) of the major national advertisers in the United States. While some ignore or downplay this evidence of increased penetration as a minor or transitory development (Wieser $2014 \mathrm{a}, \mathrm{b}, \mathrm{c}$ ), others take the data as an indication of the uncertain future of external agencies in the evolving environment of advertising services (ANA, 2013, p. 30). This sector is in the midst of a major transformation, driven by a confluence of changes altering the economic, competitive, and technological conditions under which the industry has long operated. With the entry of formidable new rivals and the introduction of innovative service models (Evans, 2008, 2009), the vertical structure of the advertising and marketing services industry that will emerge in the future looms as uncertain. Concurrently with the threat of disintermediation, the industry is contending with continuing challenges arising from globalization and somewhat sluggish recovery from the recession.

The in-house agency is clearly not a new organization form. To the contrary, internalization of advertising services within the U.S. dates back to the earliest days of the industry (Pope, 1984, Chapter 4). In the 1890s, Royal Baking Powder was among the nation's largest newspaper advertisers and maintained an in-house agency to develop and implement its campaigns. Half a century later, General Electric established an in-house agency that supplied a wide array of services to GE's portfolio of businesses for four decades (Burnside, 1991). To appreciate the resurgence of the in-house model, business leaders must first understand how the contemporary internal agency differs from its predecessors and what factors have shaped its evolution.

Whereas traditional consideration of internalizing advertising services was framed as a binary choice of build or buy (Anderson \& Weitz, 1986; Ruekert, Walker, \& Roering, 1985), today's advertisers frequently pursue hybrid policies of build and buy to procure the customized bundle required to develop, produce, and implement relevant, resonant promotional campaigns. Increasing numbers of advertisers are discovering that the demand for advertising and marketing is best served through the coordination and integration of resources from both inside and outside the company, rather than assuming that these options are mutually exclusive. The real question advertisers now face is "what services to build and which to buy" so as to assemble the particular bundle that will enable them to mount effective campaigns in a cost-efficient manner.

Our purpose here is to provide senior managers with an update on the current state of in-house agencies and to suggest that internalization of advertising services should be included in the set of options carefully considered as they address the issues surrounding the design of "the new marketing organization," as featured in the July-August, 2104 issue of Harvard Business Review (Joshi \& Gimenez, 2014; de Swaan, van den Driest, \& Weed, 2014).

We begin with a brief summary, in Section 2.0, of early history that serves to explain why internal agencies have long operated in the shadows of their external counterparts. In Section 3.0, we discuss how internal agencies have evolved over time, detailing the contemporary in-house model. We analyze the core competencies underlying that model and assess the competitive position that in-house agencies occupy in relation to external providers today. Section 4.0 presents two case examples of successful internal/external agency collaboration. Section 5.0 sets forth our conclusions.

\section{Historical Perspective}

Given that in-house agencies have existed throughout the course of advertising history (Clark, 2003), the question naturally arises as to why the role of in-house agencies has remained obscure and their status undervalued until quite recently. The answer lies in the institutional arrangements that developed during the industry's formative years.

The origin of the advertising agency in the U.S. dates back to the middle of the nineteenth century with the emergence of "space agents" who represented newspaper publishers and facilitated transactions between publishers seeking advertising revenues and advertisers seeking to communicate with geographically dispersed prospective customers. Space agents evolved to "space jobbers" who purchased advertising space from publishers and resold it to advertisers, thereby earning a commission equal to the difference between their selling and buying prices. Soon advertisers were demanding other services required to plan, design, and produce their promotions. As Pope (1984) notes, "The evolution from space broker to advertisement creator to marketing advisor was quite swift" (p. 143) and "between the 1890s and 1920 independent agencies became the suppliers of advertising services to virtually all important national advertisers" (p. 147).

Thus the modern, independent, full-service agency was born. With this expanded set of services, an agency's clients were advertisers, rather than publishers or media suppliers, as had been the case for space agents and brokers. Despite this shift, agency compensation continued to be determined by the commission earned on the space that agencies purchased from publishers on behalf of their clients. Commission rates were eventually 
standardized with the commission system of agency compensation persisting for decades as a result of what Pope aptly characterized an "alliance of convenience" (p. 153) between independent agencies and publishers. That alliance consisted of a complex set of interrelated trade practices known as the "recognition system," defined as "various policies, standards, and procedures used to qualify advertising agencies to do business with, and to be entitled to receive credit and agency commission" (U.S. District Court for the Southern District of New York, Complaint filed by the U.S. Department of Justice, 1955).

The effects of the recognition system were both far reaching and long lasting. On one hand, these trade practices served to mitigate the adverse effects of the information asymmetries and opportunism that were widespread in the early days of advertising. On the other, the recognition system essentially precluded advertisers from establishing in-house agencies and buying advertising time and/or space directly from media suppliers. The system also restricted price competitiveness among ad agencies by dissuading agencies from rebating or splitting commissions with their clients.

For decades, the recognition system was the subject of debate and litigation with advertisers opposing the practices supported by independent agencies and media outlets. Finally in 1955, federal antitrust authorities alleged that the recognition system constituted a conspiracy in restraint of trade under the Sherman Act. This led to the signing of a consent decree in 1956 by six trade associations, each representing a distinct constituency including independent advertising agencies and various categories of print publications. Among other things, the associations were prohibited from fixing agency commissions, rebating or splitting agency commissions, establishing qualifications used to limit or deny the granting of credit or commissions to agencies, and establishing special rates for advertisers not employing an independent agency (American Association of Advertising Agencies, 1956; Holland, 1981).

While the signing of the consent decree is credited with effectively dismantling the administrative structure of the recognition system (Holland, 1981), it had little or no immediate effect on agency compensation or the bundling of agency services. For reasons discussed in Arzaghi, Berndt, Davis, and Silk (2012), these twin policies gradually faded away, though slowly (Weilbacher, 2003). Cost-based fees eventually replaced media-based commissions as the dominant method of agency compensation with agencies unbundling their services and advertisers splitting their accounts across multiple firms. With the lowering of these barriers to internalization, advertisers could consider establishing their own in-house agencies as a partial or full substitute for their dependence on external providers.

Unfortunately, detailed historical information tracing the emergence of in-house agencies over time is lacking. However, two short but revealing time series are available relating to the penetration of in-house agencies - specifically, the share of advertisers for whom certain services were provided internally. Data covering the period 1924-33 were reported in a study sponsored by the Association of National Advertisers (Haase, Lockley, \& Digges, 1934). The share of all advertisers listed in a comprehensive trade directory who reported negotiating their own media placements was found to be approximately $24 \%$ from 1924 to 1927 . That share declined to $19 \%$ in 1929 , just prior to the onslaught of the Great Depression, turning upward to $28 \%$ in 1933, which is the last year the measure was reported.

Fast forward half a century, the share of advertisers of all sizes who reported the use of at least some in-house advertising resources was approximately 50\% in 1990 and 1999 (Horsky, Michael, \& Silk, 2012). These measures of internalization do not distinguish between "partial" and "full" integration and thus include cases of mixing internal and external services. The existence of such hybrid policies was often noted but not formally tracked. There is a considerable body of fragmentary evidence (e.g., Horsky, 2006; Newton, 1965) suggesting that the utilization of in-house agencies became widespread far earlier than what has generally been acknowledged.

\section{The Contemporary In-House Agency: Evolution and Core Competencies}

The majority of in-house agencies were initially formed in response to utilitarian requests-assignments that were neither strategic nor creative but tactical in nature, requiring swift, low-cost creative execution. These organizations were typically comprised of desktop publishers, hired by the corporation to fulfill reactive requests from sales agents and design inconsequential-yet-essential collateral materials.

It has long been noted that the internalization of advertising services varies widely across industries (Horsky, Michael, \& Silk, 2012). Financial services, technologically-intensive manufacturers, and government agencies were among the early adopters of this model. In those industries, it was recognized that investment in dedicated internal resources was needed to develop highly specialized, industry-specific materials at the desired level of cost, quality, and dependability. Market demand for the focused expertise required to develop such "collateral" is 
limited and hence unattractive, if not incompatible, with the business model of mainstream independent agencies (Kahn, 1986).

With the majority of low-cost, quick-turn tactical assignments being funneled in house, external agencies were left to focus on work that was advantaged by their specialized services-where the economics of scope, scale and related synergies could be more fully leveraged. At this stage, insourcing was not a direct threat to external agencies whose focus was providing strategic, creative services in support of well-funded national campaigns placed in highly visible, "above-the-line" media. That "low cost and quick turn" has long been understood as the prime rationale underlying the internalization of collateral advertising is consistent with the theory and empirical research on the economics of vertical integration more generally (Lafontaine \& Slade, 2007; Williamson, 2010; Horsky, Michael, \& Silk, 2012). Over time, however, the project work that was apportioned to in-house agencies grew in both volume and complexity, primarily due to an insatiable corporate appetite for cost savings and control.

As the work grew, so did the infrastructures required to support it. Project managers were added to internal design teams as liaisons between those requesting the work and those doing it. Writers were added to develop messaging content, formerly provided by internal clients themselves. Production specialists came onboard to bid projects and manage vendors. Some corporations even added media buying, as significant savings could be realized now that internal agencies were able to purchase media space at equivalent prices to external agencies. As demand for internalized services and supporting infrastructures increased, so did the advertising expertise that in-house agencies could claim.

With corporate commitment and the sophistication of in-house talent advancing, the line between advertising produced inside and out eventually blurred. This resulted in concern that internal agencies were encroaching on their external counterparts, decreasing the potential for revenue and growth among outside firms. That concern was punctuated by a 2013 ANA study that drew attention to the rising corporate utilization of in-house agencies and the expanding scale and scope of services offered internally. The study indicated that the majority (58\%) of U.S. advertisers employ internal agencies - up from $42 \%$ in 2008. Reflecting on this rise, ANA Group Executive Vice President Bill Duggan remarked: "Fast, cheap, good - pick two. Almost every marketer and agency exec has heard that quote. For years, in-house agencies were known as being fast and cheap, but not necessarily good. Now, many are good-in fact, very good!” (ANA, 2013, p. 21).

Extending this perspective, it is clear that the core competencies underlying the contemporary in-house model reflect both continuity and change. We label these capabilities as efficiency, adaptability, and corporate influence. In exploring these themes further, we draw upon recent field investigations specific to the current state of in-house agency operations emanating from two distinct sources. The first is the Association of National Advertisers (ANA) who in 2008 and 2013 surveyed its membership of over 500 U.S. corporations with respect to their utilization of internal agencies. Our second source is the In-House Agency Forum (IHAF), founded in 2005 to support the unique interests of internal advertising and creative services organizations owned and operated by parent firms. IHAF has been conducting quarterly field studies specific to in-house agency operations, staffing, compensation, and performance since its inception. As of Q2 2015, IHAF has a national membership of nearly 200 internal agencies.

\subsection{Scope of Service Offerings}

The purpose and utilization of advertising varies greatly across industries as well as among corporations within the same industry. So too does the range of services sought by advertisers and supplied by agencies, independent and in house. Advertising services can be classified along two dimensions: (1) the task or function performed (referred to as "disciplines" in advertising trade circles), and (2) the communications media employed to reach target audiences.

Cross classifying a standard set of tasks with a simplified grouping of communications media, we obtain the matrix of services shown in Table 1. The columns list functions/disciplines, including those traditionally offered by full-service agencies (account management, creative development, media planning and buying, production of materials, marketing research, public relations, etc.) The rows recognize highly aggregated forms of communications outreach which can be easily extended to represent a further refined taxonomy of media. 
Table 1. Matrix of agency services

\begin{tabular}{|c|c|c|c|c|c|c|c|}
\hline \multirow[b]{2}{*}{$\begin{array}{l}\text { COMMUNICATIONS } \\
\text { MEDIA }\end{array}$} & \multicolumn{7}{|c|}{ AGENCY DISCIPLINES/FUNCTIONS } \\
\hline & $\begin{array}{l}\text { Account } \\
\text { Management }\end{array}$ & $\begin{array}{l}\text { Creative } \\
\text { Development }\end{array}$ & $\begin{array}{l}\text { Media } \\
\text { Planning \& } \\
\text { Buying }\end{array}$ & $\begin{array}{l}\text { Production } \\
\text { of Materials }\end{array}$ & $\begin{array}{l}\text { Marketing } \\
\text { Research }\end{array}$ & $\begin{array}{l}\text { Public } \\
\text { Relations }\end{array}$ & Other \\
\hline \multicolumn{8}{|l|}{ Traditional Media } \\
\hline \multicolumn{8}{|l|}{ Print } \\
\hline \multicolumn{8}{|l|}{ Broadcast } \\
\hline \multicolumn{8}{|l|}{ Out of Home } \\
\hline \multicolumn{8}{|l|}{ New Media } \\
\hline \multicolumn{8}{|l|}{ Digital } \\
\hline \multicolumn{8}{|l|}{ Social } \\
\hline \multicolumn{8}{|l|}{ Mobile } \\
\hline Other & & & & & & & \\
\hline
\end{tabular}

The customized ensemble of services required to plan, develop, and implement an advertising campaign can be represented by the intersections of the relevant rows and columns of the matrix. In principle, each discipline could be supplied by an in-house agency or an external agency. Note that even in the relatively simple case of deciding whether to make or buy each of, say, four services (creative, media, production, and research; for a single medium, say print), there are $2^{4}$ or 16 possible options that might be considered.

Four observations about the demand and supply of advertising services represented in Table 1 bear noting (Silk \& King, 2013). First, over time the array of advertising services that exists in the marketplace has expanded significantly - the number of rows and columns that define the matrix has grown. Functional columns were added as agencies evolved from media brokers to full-service providers. Advances in technology have also resulted in a proliferation of options for communicating with target audiences as indicated by the rows of "New Media."

Second, from the portfolio of services offered by agencies, clients select the subset that meets their needs, thereby forming customized bundles to fit their requirements. This customization accommodates the heterogeneity among advertisers arising from differences in products and markets served (i.e., industry participation) and corporate strategy with respect to marketing.

Third, the practice of combining internal and external advertising services is not new. The extent to which advertisers have relied on a combination of inside and outside resources to satisfy demand has been subject to shifts over time with wide variability across industries and companies (Horsky, Michael, \& Silk, 2012).

Fourth, the design of a customized bundle of services that utilize both internal and external sources of supply poses a complex allocation problem because of interdependencies among the set of disciplines/functions shown in Table 1 due to several phenomena including the presence of scale and scope economics (Silk \& Berndt, 1993, 2004) and the need to integrate multifaceted communication programs. Given such interdependencies, changes in assignments induce mutual adaptation among the ensemble of services illustrated in Table 1. See Novak and Wernerfelt (2012) for a study of how interdependencies and mutual adaptation affect make-or-buy decisions in the supply chain of the global automobile industry. Wernerfelt (2015) contrasts transactions that occur in markets with those that are carried out within firms and then develops an analysis of the optimal size of markets and scope of firms.

\subsection{Core Competencies}

With the mixing and matching of advertising services on the rise, a comparison of the core capabilities associated with internal and external agencies serves to illuminate the underlying economic rationale behind this hybrid practice. Whereas "expertise, specialization, and objectivity" have long been the watchwords of external agencies (Pope, 1982, p. 141), "efficiency, adaptability, and corporate influence" stand out as the mantra of today's in-house teams.

\subsubsection{Efficiency}

Numerous articles have appeared in the trade press comparing the advantages and disadvantages of internal and external agencies (e.g., Pulver, 1979). A recurring theme has been that in-house agencies are low-cost, quick-turn operations that supply a limited range of auxiliary services.

As stated earlier, the majority of internal agencies began by focusing on recurring tasks that required 
industry-specific or firm-specific knowledge and skills, euphemistically labeled as collateral services. Prototypical examples are direct mail and sales-support materials such as postcards, brochures, and flyers that are routinely used in the marketing of industrial and technology-based products as well as financial services.

The aforementioned 2008 and 2013 ANA studies found that more than $90 \%$ of reporting in-house agencies supplied promotional materials disseminated through traditional media (ANA, 2013, p. 11). When asked to identify the advantages of having an in-house agency, $88 \%$ of respondents to the 2013 ANA survey indicated "cost efficiencies" and 71\% mentioned "quicker turnaround times" (ANA, 2013, p. 22).

Measuring efficiency has become increasingly important for internal teams to prove their value - particularly through the downturned economy. A recent IHAF field study indicates that $51 \%$ of in-house agencies regularly track and report metrics associated with operational effectiveness, e.g. employee utilization/billability, budget-versus-actual reporting, and ability to meet project deadlines (IHAF, 2014, p. 17).

For in-house agencies, the ability to scale up and down with demand is critical. One of the ways we do this is by making sure our structures are not too fixed, enabling our organizations to be nimble. On the other hand, we are also being tasked with cost containment which can cause us to build operations that are so focused on efficiency that we inadvertently build rigidity into the system-rigidity that doesn't allow us to respond quickly or operate as nimbly as we should (Stiglin, p. 3).

Respondents to that same IHAF study indicated that hiring and headcount limitations (64\%), organizational design and structure issues (57\%), and budget limitations not related to headcount (54\%) are among the leading challenges in-house agencies face in taking efficiency further (IHAF, 2014, p. 19).

\subsubsection{Adaptability}

In-house agencies have long been known for their ability to respond to the frequently changing, time-sensitive demands of their corporate clients. More recently, these teams are gaining recognition for their adaptability in response to new technologies, new forms of outreach, and market globalization.

The advent of digital media has prompted transformation across the industry, opening new channels for consumer engagement while affecting the economics of advertising and marketing services as well as the management of campaigns (Evans, 2008, 2009). Burton (2009) analyzed the relative costs of services for digital and traditional media campaigns and drew attention to "the shift from external third-party production resources to in-house agency resources:"

As marketers migrate more activities to the Digital world, the scale and volume of these projects has led the industry to hire and develop internal capabilities to efficiently produce Digital programs...This shift from out-sourcing to in-sourcing holds true for small independent shops as well as large global agency networks. It also has reduced many of the barriers to entering the agency space (p. 11).

Consistent with this, the 2013 ANA study found that over a prior three-year period, $52 \%$ of advertisers with in-house agencies had assigned additional responsibilities related to digital, social, and mobile media to in-house resources as opposed to external agencies (ANA, 2013, p. 17). IHAF's 2014 operations study reveals that print projects comprise half of the annual work produced in house, with digital accounting for $30 \%$ and video for $9 \%$ (IHAF, 2014, p. 7).

Supporting global strategies and markets is another area where internal agencies have advanced. In 2011, IHAF issued a whitepaper forecasting the expanded role that in-house teams would take in the international marketplace:

Internal advertising and creative services organizations are expected to have the people and processes in place to successfully support the emerging needs of their global affiliates by leveraging existing assets and developing new materials (Stiglin, 2011, p. 2).

The executives interviewed for that paper indicated that their teams were focused on establishing best practices that would encourage people to think about engagement from a global perspective versus viewing it through a domestic lens (IHAF, 2011, p. 2). The latest ANA study corroborates this, indicating that $43 \%$ of internal agencies support advertising programs in both domestic and global markets (ANA, 2013, p. 21).

Measuring client satisfaction has also become a common practice among internal agencies. The ANA indicates that $71 \%$ of in-house teams solicit feedback from their clients (ANA, 2013, p. 29), enabling them to consider their performance and adjust accordingly. IHAF recently introduced a customizable, online survey specifically designed to enable internal agencies to measure client satisfaction and team performance. The emergence of such tools speaks to the continuous improvement mentality that many internal agencies embrace — not only measuring satisfaction but also quantifying the value and impact of their work. 


\subsubsection{Corporate Influence}

Paralleling their expanded scale and scope of services, in-house agencies have elevated their status with internal and external constituents. The essence of being "in house" is proximity and access to information (Silk, 2012). This provides internal agency personnel with limitless opportunities to listen and learn from within, acquiring company-specific and industry-specific knowledge and insights, forming deep client relationships, and influencing the business directly.

Two-thirds to three quarters of advertisers in the ANA's 2013 study cited "institutional knowledge" and "brand expertise" as leading advantages of their in-house agencies (ANA, 2013, p. 22). Not only is that experience brought to bear in the development of promotional materials but in the deployment of those assets, particularly in the digital arena.

Being positioned at the heart of company also gives in-house agencies visibility to real-time challenges and the opportunity to affect business strategies, enabling them to collaborate with clients early and often. Increased frequency of engagement, particularly with executive decision makers, means in-house teams are influencing everything from strategic planning and positioning to brand integration and campaign management.

The "new" internal agency differs from the outdated stereotype in that in-house teams have advanced from order takers to partners, working hand in hand with their clients to develop and execute strategies in support of business and brand objectives.

\subsubsection{Competitive Position}

The widening scope of service offerings coupled with gains in penetration underscores the sharp contrast between the standing of the contemporary in-house agency and the stereotype of its predecessors. This shift is reflected, once again, in the 2013 ANA study, which found that in the previous three years, $56 \%$ of responding national advertisers with internal agencies have moved established business that had previously been handled by external agencies in house (ANA, 2013, p. 15). Interestingly, the study also revealed that among those companies with a marketing procurement department, $45 \%$ indicated that the procurement group had some influence over moving the business from an established external agency to internal resources (p. 18).

Another indication of the competitive position of in-house agencies is the rising share of national advertisers who view the relationship between their internal and external agencies to be one of complementarity rather than substitution. Whereas in 2008 , the ANA study found that $41 \%$ of advertisers characterized their in-house agencies as "partners" with their outside agencies, by 2013 that share had grown to 56\% (ANA, 2013, p. 25). Moreover, the share of advertisers who viewed the relationships between their in-house and external agencies as competitive dropped from $18 \%$ in 2008 to $10 \%$ in 2013.

Notwithstanding the data, lingering sentiments of competitiveness and elitism remain throughout the industry. While client-side marketers are poised to embrace complementarity, external agency holdouts, including clusters of the advertising trade press, have not been as quick to come around-particularly when it comes to acknowledging the quality of personnel resident in house.

The ability for internal agencies to attract and retain top talent to deliver cutting-edge, strategically sound creative services continues to be questioned despite numerous indicators suggesting that such limitations have diminished over time. For example, examining the leaders of the four internal agencies featured at IHAF's 2013 In-House Agency Masters conference (Bose Corporation, Metro Los Angeles, Prudential Financial, and Timex), three had over a decade of experience working for well-known external agencies with the fourth being an executive who has been with his parent company for over two decades.

While the stigma associated with strategic and creative talent on the in-house agency side has slowly eroded, it has not been eradicated. In the ANA's 2008 study, "lack of depth of strategic thinking," was cited by $61 \%$ of respondents as the chief disadvantage of working with an internal agency. By 2013, that statistic had dropped by half (30\%), suggesting that internal agencies have considerably boosted their strategic profiles. Beyond strategic thinking, the 2013 ANA study revealed an inability to stay on top of key trends (45\%), lack of creative innovation (43\%), and skillset limitations (41\%) as the leading disadvantages of working with internal agencies (ANA 2013, p. 24) indicating that in-house teams still have a ways to go.

Not surprisingly, industry opinion is divided on the subject of how much of a threat insourcing poses to the future of external agencies. Some see the rise of in-house agencies as a major development. Bob Liodice, President and CEO of the ANA, suggested that "the growth trajectory of advertising agencies is in question as marketers move existing and emerging functions in-house." Liodice went on to "urge our agency peers to adapt to this new reality and offer even greater value to avoid gradual disintermediation with clients" (ANA, 2013, p. 
30).

Conversely, others regard the inroads of in-house agencies as minimal. A leading financial analyst and longtime observer of the ad industry dismisses the notion that internalization is a significant trend and foresees that "most marketers who try to bring more work in house will discover it's not for them; some will find it works out." He foresees the industry continuing to evolve but with few structural changes:

In the grand scheme of things, threats of agency-marketer disintermediation shouldn't be of much concern. Agencies are always mindful of finding ways to retain business in one form or another. Larger marketers always look to find ways to reduce fees for like-for-like efforts, and are usually successful...Agencies don't die easily; they usually just evolve, and usually for the better (Wieser, 2014c).

Certainly this last point applies to agencies of all types — external and internal.

\section{Internal/External Agency Collaboration: Two Case Examples}

As the boundaries that traditionally separated the work streams, functional capabilities, and technical talents of internal and external agencies have faded, the debate over whether the two are complementary or competitive has intensified - that is, with the exception of those corporations that have successfully integrated their internal and external resources to arrive at a cooperative model.

\subsection{Prudential Financial and Droga5}

Prudential Financial is a leading global financial services company that markets a broad portfolio of life insurance, retirement, and investment products and services to individual and institutional customers. Founded in 1875, Prudential Financial has more than a trillion dollars of assets under management. In 2013, the firm spent an estimated $\$ 93.7$ million on advertising in measured U.S. media.

"I don't think about two agencies. I just think about resources," said Colin McConnell, Chief Brand Officer and head of Prudential Advertising, the 70-person in-house agency that is owned and operated by Prudential Financial. "They're here all the time. It feels like they are just part of the team-part of our normal operating rhythm."

The "they" McConnell refers to is Manhattan-based creative powerhouse, Droga5-Prudential Advertising's partner since 2010. "Of course, I'm aware that each of us has a different culture and different ways of doing things. That's the price of admission for a partnership like this. If Droga5 were to operate exactly the way we do, what's the point? We respect each other enough that if this is how each of us simmers the sauce, we let it happen that way because the output is good." And the output is very good, with their collective efforts on Prudential's highly lauded Bring Your Challenges campaign as well as their Day One and Chapter Two initiatives earning national recognition for both organizations, better yet, their combined team.

The collaborative relationship between Prudential Advertising and Droga5 began following the formation of Prudential Financial's U.S. Marketing Council, established to "guide the brand for the next decade." To achieve its long-term objectives, executives at Prudential knew that the company needed to increase its marketing investment and in doing so that they needed to increase their advertising capacity.

The Prudential brand has long been a nostalgic one, in part because of its rich history and in part because of its operating philosophies. McConnell and his colleagues recognized this and decided that in order to do something truly distinct, they needed an external perspective that could help them see the brand differently and extend it into new spaces.

McConnell embarked on an agency review, stipulating that the in-house team would be part of the pitch and that regardless of who won, the internal agency would maintain ownership for a certain percentage of the work, including media strategy and buying. Ultimately the pool of agencies considered was narrowed to four- three external providers and the in-house team.

In the last round of the review McConnell recalls, "I could tell by their body language when (Droga5) came in that they felt good. When they unveiled the first canvas, I knew they had it." Although the pitch concept never ran, McConnell believes that it was at this point that collaboration was born. "We said, 'We really like you guys, but we can't run this campaign the way it looks now. Don't worry though, we'll fix it together.' And that's when things got interesting."

Droga5 let McConnell and his team in on their creative process, and Prudential Advertising guided Droga5 through important nuances of the campaign. It was challenging at first, as neither team was accustomed to operating this way and both had enormous pride in their work. Eventually, Bring Your Challenges emerged from an idea initiated by Droga5, with the in-house agency codifying and communicating the concept internally as 
well as leveraging it to evolve the corporate strategy.

Strategy development continues to be an area where the two are adept at working together. Resource sharing is another, with Prudential Advertising's heads of account service and production working closely to both direct and support Droga5. McConnell is cautious and deliberate in his choice of words to describe how the relationship works. "From the beginning, I've tried to inculcate this whole thing: there is no 'us' and 'them,' it's just us. They're in NY. We're in Newark. But we're all on the same team."

Kevin Brady, Executive Creative Director for Droga5, agrees. "We refer to ourselves as co-agencies. We each have our own area where we play, but we also switch back and forth pretty fluidly. There are times when an idea begins with someone at Prudential — the creative director or writer or designer — and they send it over saying, 'Here's something we're working on, do you guys want to work it too?' We take their idea and add water to help it grow. And they do the same with us." Group Account Director, Heidi Rick adds, "Because of the depth of knowledge at Prudential Advertising, they are pivotal in helping us frame the problem. It's not the typical client relationship where we walk in and present final work. It's an iterative process where we look at things together at an institutional level yet through a creative lens."

One area where there is delineation of responsibility is media strategy and buying, led by Prudential Advertising. Even with ownership clearly defined, the two agencies are looking to strengthen collaboration between Prudential's media department and Droga5's creative group. "It's a major opportunity," says McConnell. "Advertising in general has moved away from 'the big idea' to incubating lots of smaller ideas in low-cost, highly targeted often social settings. Doing this well requires agility between the creative department, the media department, and the publisher."

It's this type of agility that's up next on the agenda for Prudential Advertising and Droga5 as they recognize the need to overcome the physical divide between offices, "It sounds a bit silly," McConnell discloses, "but the mere separation of 10 miles across the water in New York makes a huge difference. It's not as easy as walking down the hall and just talking to the creative team."

From Droga5's perspective that bit of separation can have its upsides. "There's something fresh about being immersed in the client but not so far immersed that you forget what it's like to be the consumer," says Brady. "I think that's one of the strengths each of us brings to the table as our unique superpower. We can see this financial world without being too close, so part of our superpower is lack of proximity and lack of knowledge in a way. We're able to give a different long view while the in-house agency can still say, 'That long view is great but let's bring it back to reality.' Our individuality makes us stronger together."

As Prudential Advertising and Droga5 continue to advance their cooperative construct, it is clear that both organizations have the same end-game in mind: to move away from the traditional assembly-line model where clients request a project and it makes its way from agency function to agency function until it hits the marketplace. Instead, they are looking to further unite their resources to make an even greater impact on the business. "Our goal is for everyone to be working together-media people, creative people, production people and strategists all sitting around the table looking at the same object at the same time," says McConnell, "That's how the really interesting work gets done."

\subsection{The Boeing Company's Multi-Agency Model}

At The Boeing Company, the story of internal/external agency collaboration begins with a corporate strategy initiated by CEO Jim McNerney - a strategy to unite Boeing's commercial, defense and enterprise divisions under a single internal brand known as One Boeing.

"We are one Boeing," said Fritz Johnston, retired Vice President of Global Brand Management and Advertising, "not only in how we present ourselves but in how we practice as business units. When we work together effectively, we are able to deliver the greatest product for the least cost on a worldwide basis."

Boeing is the world's largest aerospace company and the leading manufacturer of commercial jetliners and military aircraft combined. The company also designs and manufactures rotorcraft, electronic and defense systems, missiles, satellites, launch vehicles and advanced information and communication systems. In 2013, Boeing spent an estimated $\$ 19.4$ million on advertising in U.S. measured media.

From an advertising resource perspective, Boeing's commitment to cooperating locally and integrating globally is what prompted Johnston to assemble a family of agencies to satisfy the company's promotional needs. As a multinational manufacturer, Boeing has long been known for partnering with suppliers who are leaders in their respective fields. Their approach to advertising is no different. "The reason we work with multiple agencies," said Johnston, "is that they all bring different expertise to the table. It's not about any one agency; it's about 
driving One Boeing in a way that benefits the brand."

The easiest way to think about Boeing's multi-agency relationships is by medium. Foote, Cone \& Belding (FCB) out of Chicago focuses on Boeing's international and tribute advertising, as well as TV/video production. Frontline in Los Angeles focuses on print, broadcast and messaging strategy. R\&R Partners in Phoenix is focused on digital marketing and Boeing's web properties. Methodologie in Seattle is focused on brand strategy and visual brand identity. TMP Worldwide in Chicago focuses on recruitment advertising. And Creative Services, Boeing's own 220-person agency, focuses on integrating and iterating it all-pushing work out to various markets in order to enable scale.

A few years ago, Johnston, whose role influenced all Boeing agencies internal and external, had called for a thorough review of the internal Creative Services organization. "Fritz knew we needed more strategy, more collaboration, and more power from the internal team," said Jim Newcomb, Director of Global Brand Management at Boeing. After a two-year restructure, the internal agency is on the path Johnston envisioned. "We've added talent, processes and training," said Wayne Barringer, Boeing's Director of Creative Services. "We're starting to drive more strategy and collaborate in a much more involved way."

"Boeing is so big and there is so much work that we can't see it all, we can't handle it all, and we can't control it all," said Scot Havrilla, SVP and Group Management Director at FCB. "Having the in-house agency working with us to establish the platform and then carrying it forward into all the nooks and crannies of Boeing is invaluable."

So how does this multi-billion dollar brand manage its multi-agency model? Four times a year, the internal and external agency leads gather in the same city and spend a day reviewing current and future initiatives. "From the beginning I set the stage for collaboration by telling them, 'There's huge talent sitting in this room right now. I know all of you have egos and such, but I'm going to ask you to put all that aside'," recalled Johnston. "I said, 'This is not about any one agency or who is gifted at delivering - it's about the Boeing brand. We're all going to focus on that. We're all going to drive toward that."”

The agencies also assemble monthly via conference call to review metrics and discuss what's working and what's not-including how effectively their respective teams are operating together. High-touch, deliberate communication among agencies combined with strong, steady leadership at Boeing is what has enabled the success of the paradigm.

"Fritz (Johnston) was such a strong proponent of communication," commented Dale Hart, Chief Creative Officer with Methodologie. "More than email, he wanted a phone call. More than a phone call, he wanted us all in the same room. More than being in the same room, he wanted us talking to each other one on one. Our challenges have been few because we all know our respective roles and there's a clear captain in place. Role clarity, communication, collaboration, how it's working, and trust all point back to one thing-leadership. That's the central theme."

Leadership was also central to the development of Boeing's new brand platform, Build Something Better-an effort that most of the agencies described as their most collaborative yet.

The assignment was to update the brand guidelines for the corporation. The process started by bringing all of the agencies together, internal and external, and surfacing issues related to the brand, discussing what could be improved, and cooperating on the development of what was eventually published as a new set of standards. Given their expertise in brand strategy and identity, Methodologie took the lead on the project, though the perspectives of all of the agencies factored into the solution.

"As we developed the style of the brand, we looked to Frontline to develop the voice. And since we don't do advertising, we looked to FCB for their expertise there," said Hart. "The internal agency is best at knowing Boeing, so we relied on them to navigate the product and the politics."

"Sometimes the most important perspective is the internal one and being behind the fire wall both literally and figuratively is vital to the success of a project," said Matt Mason, Chief Creative Officer with R\&R Partners. "Boeing is 160,000 people spread across every nation on Earth. It's very difficult for an external agency to roam the halls and get approvals and iterate the work where it needs to be done-almost impossible. The value Creative Services brings to this collaborative environment is that they sit on the inside whereas the rest of us sit on the outside."

Most of Boeing's external agency contracts stipulate that a certain percentage of their compensation be tied to collaboration. For the in-house agency, collaboration is written into their business goals and objectives. Measurement comes in the form of surveys and outcomes related to specific assignments. There are also a 
handful of people at a senior management level within Boeing who are tracking how effectively the teams are cooperating.

"For collaboration to work there has to be trust," said Mason of R\&R, "and for trust to exist there needs to be relative calm in terms of knowing your service areas. It's critically important to establish clear scopes of work and to engender a sense of 'Here's what we expect from you and here's what we expect from them.' Once that's been settled, I think multiple agencies can collaborate quite well."

FCB's Havrilla added, "We've gotten to the point where if it's ever confusing, we just ask Boeing, 'who do you want to own what parts of this' or we figure it out ourselves. I have to give credit to Matt (Mason) who said early on, 'Hey guys, no shoot-outs because shoot-outs will break it all down.' When you have a shoot-out, you put one team up against another to gain an assignment. Any time that happens, trust dissipates because there's a winner and a loser. No one wins in that case."

All of the agencies credit Boeing for setting up an environment that feels safe for them to participate as equals. "The real hero here is Boeing," continued Havrilla, "because it doesn't happen without them. Over time, Boeing has moved us from thinking of ourselves as individual agencies to thinking of ourselves almost like the knights of the creative roundtable. They brought us all together and now we're listening to one another."

"I have a lot of respect for the discipline and the vision Boeing has demonstrated in crafting something like this," concluded Mason of R\&R. "And I give their internal team a lot of credit for their willingness to support it. This is completely unique for our agency; I don't have any other client relationships like it."

"The journey from an internally focused service organization to a collaborative agency structure is a long one," concluded Barringer, Boeing's in-house agency lead. "But the One Boeing Fritz envisioned - the unprecedented external agency collaboration combined with a stronger, more strategic internal team-demands that type of transformation."

\section{Conclusions}

The internalization of advertising services is on the rise. Research shows that not only is the penetration of in-house agencies increasing, but the scale and scope of those operations is expanding as well. These developments are part and parcel of the restructuring of the advertising and marketing services industry currently underway in response to the challenges and opportunities accompanying the adoption of digital technology, globalization, brand integration, and cyclical economic conditions.

The model of today's in-house agency is built upon a foundation that begins with its traditional capacity for "efficiency," enhanced by an expanded set of competencies that includes "adaptability" and "corporate influence." As a result, assembling the particular bundle of services to enable a corporation to mount effective communications campaigns requires marketers to reframe their policy choices with respect to advertising services by considering what to build and what to buy.

As illustrated by the case examples of Prudential Financial and The Boeing Company, advertisers are adopting hybrid policies wherein they mix and match internal and external resources to deliver the customized bundle of services they require. The successful collaboration of the agencies featured also suggests that both internalization and mixed policies of insourced and outsourced services are likely to prove to be sustainable features of the marketing industry.

Those considering bringing their internal and external agency resources together to arrive at a more-collaborative operating model would be well served to include the following the practices as part of their implementation process:

1) Alignment on purpose and objectives - ensuring that both internal and external agencies are fully aligned around a common purpose and that the relationship is set-up in such a way that both groups are moving toward a shared objective.

2) Clarity of roles and responsibilities - individual roles and responsibilities are clearly communicated and understood, enabling participants within each agency to recognize what should be communicated from one to another.

3) Streamlined operating practices - the combined team is optimally organized to evolve shared, streamlined operating practices and a disciplined approach to work that enables efficient decision making and integrated implementation.

4) Exchange of ideas and resources - members of the internal and external agencies willingly exchange ideas, insight and resources with each other, for a level of mutual support that enables individual and team 
performance.

5) Skilled, centralized leadership - the combined team is effectively guided, motivated and inspired by an accomplished, shared leader who fosters a culture of performance, partnership and accountability.

While the in-house agency is not a new phenomenon, the contemporary version is quite different from its predecessors. Internal agencies have come into their own, having broken the stereotype of "fast and cheap" as they move toward new relationships and increased potential for partnership with their base of internal clients and collaboration with external providers.

\section{Acknowledgments}

The support of the Division of Research, Harvard Business School, is gratefully acknowledged. Thanks are due to John Quelch and Steve Michael for helpful comments. Co-authors, Alvin Silk and Marta Stiglin, contributed equally to the development of this article.

\section{References}

American Association of Advertising Agencies. (1992). Questions and Answers Pertaining to the Settlement of the Antitrust Action with Respect to the A.A.A.A. New York.

Anderson, E., \& Weitz, B. A. (1986). Make or Buy Decisions: Vertical Integration and Marketing Productivity. Sloan Management Review, (Spring), 3-19.

Arzaghi, M., Berndt, E. R., Davis, J. C., \& Silk, A. J. (2012). The Unbundling of Advertising Agency Services. Review of Marketing Science, 10(1), Article 4. http://dx.doi.org/10.1515/1546-5616.1164

Association of National Advertisers. (1976). Current Trends in Advertiser Practices in Compensating Their Agencies. New York.

Association of National Advertisers. (2008). 2008 In-House Agency Survey: Key Findings, New York.

Association of National Advertisers. (2013). The Rise of the In-House Agency: 2013 ANA Survey Report.

Burnside, J. R. (1991). The Selling of General Electric. Schenectady, NY: High Peeks Press.

Burton, J. (2009). A Marketer's Guide To Understanding the Economics of Digital As Compared To Traditional Advertising and Media Services. New York: American Association of Advertising Agencies.

Clark, C. (2003). House Agency. In J. McDonough \& K. Egolf (Eds.), The Advertising Age Encyclopedia of Advertising (Vol. 2, pp. 817-818). New York: Fitzroy Dearborn.

Evans, D. S. (2008). The Economics of the Online Advertising Industry. Review of Network Economics, 7(September), 351-391. http://dx.doi.org/10.2202/1446-9022.1154

Evans, D. S. (2009). The Online Advertising Industry: Economics, Evolution, and Privacy. Journal of Economic Perspectives, 23(Summer), 37-60. http://dx.doi.org/10.1257/jep.23.3.37

Haase, A., Lockley, L., \& Digges, I. W. (1934). Advertising Agency Compensation: Theory, Law, and Practice. New York: Association of National Advertisers.

Holland, D. R. (1981). The Great Tradeoff. Advertising Age, 51(6), 41-42.

Horsky, S. (2006). The Changing Architecture of Advertising Agencies. Marketing Science, 25(July-August), 367-383. http://dx.doi.org/10.1287/mksc. 1060.0198

Horsky, S., Michael, S. C., \& Silk, A. J. (2012). The Internalization of Advertising Services: Am Inter-Industry Analysis. Review of Marketing Science, 10(1), Article 2. http://dx.doi.org/10.1515/1546-5616.1142

In-House Agency Forum. (2013a). 2013 IHAF Report: Work/Life Balance Sheet. Boston: IHAF, September.

In-House Agency Forum. (2013b). 2013 IHAF Annual Conference: In-House Agency Masters. Boston: IHAF, October.

In-House Agency Forum. (2014). 2014 IHAF Report: Are We There Yet? Boston: IHAF, July.

Joshi, A., \& Gimenez, E. (2014). Decision Driven Marketing. Harvard Business Review, 92(July-August), 64-71.

Kahn, H. L. (1986). Your Own Brand of Advertising for Non-consumer Products. Harvard Business Review, 64(January-February), 24-28.

Lafontaine, F., \& Slade, M. (2007). Vertical Integration and Firm Boundaries: The Evidence. Journal of Economic Literature, 45(September), 629-685. http://dx.doi.org/10.1257/jel.45.3.629 
Newton, D. A. (1965). Advertising Agency Services: Make or Buy? Harvard Business Review, 45(July-August), 11-118.

Novak, S., \& Wernerfelt, B. (2012). On the Grouping of Tasks into Firms: Make-or-Buy with Interdependent

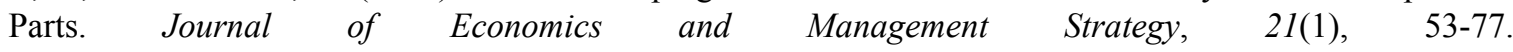
http://dx.doi.org/10.1111/j.1530-9134.2011.00322.x

Pope, D. (1983). The Making of American Advertising. New York: Basic Books.

Pulver, R. E. (1979). Advertising Services: Full-Service Agency, A La Carte or In-House? New York: Association of National Advertisers.

Ruekert, R. W., Orville, C., Walker, Jr., \& Roering, K. J. (1985). The Organization of Marketing Activities: A Contingency Theory of Structure and Performance. Journal of Marketing, 49(Winter), 13-25. http://dx.doi.org/10.2307/1251172

Silk, A. J. (2012). Conflict Policy in Advertising Agency-Client Relations: The Problem of Competing Clients Sharing a Common Agency. Foundations and Trends in Marketing, 6(2), 63-149.

Silk, A. J., \& Berndt, E. R. (1993). Scale and Scope Effects on Advertising Agency Costs. Marketing Science, 12(Winter), 53-72. http://dx.doi.org/10.1287/mksc.12.1.53

Silk, A. J., \& Berndt, E. R. (2004). Holding Company Cost Economies in the Global Advertising and Marketing Services Business. Review of Marketing Science, 2(June), Article 5. http://dx.doi.org/10.2202/1546-5616.1015

Silk, A. J., \& King, C. III. (2013). How Concentrated Is the U.S. Advertising and Marketing Services Industry? Myth vs. Reality. Journal of Current Issues and Research in Advertising, 34(2), 166-193. http://dx.doi.org/10.1080/10641734.2013.754721

Stiglin, M. (2013). Internal to International: It's a Small World After All. Boston: IHAF, March.

Stiglin, M. (2014). 2014 IHAF Report: Are We There Yet? Boston: IHAF, July.

United States District Court for the Southern District of New York. "Complaint: United States of America vs. American Association of Advertising Agencies; American Newspaper Publishers Association; Agricultural Publishers Association; Associated Business Publications; Periodical Publishers Association of America; Publishers Association of New York," Civil Action No.300-109. May 12, 1955.

Van den Driest, F., \& Weed, K. (2014). The Ultimate Marketing Machine. Harvard Business Review, 92(July-August), 54-63.

Weilbacher, W. (2003). Commission System. In J. McDonough \& K. Egolf (Eds.), The Advertising Age Encyclopedia of Advertising (Vol. 1, pp. 350-361). New York: Fitzroy Dearborn.

Wernerfelt, B. (2015). The Size of Markets and the Scope of Firms. Unpublished paper, Sloan School of Management, Massachusetts Institute of Technology, March 15. http://dx.doi.org/10.2139/ssrn.2578811

Wieser, B. (2014a). Mediations on Agency Disintermediation. Madison and Wall Street (March 28). New York: Pivotal Research Group.

Wieser, B. (2014b). Agencies: P\&G, Apple News Negative for PUB, OMB, Limited Industry Impact. Madison and Wall Street (June 5). New York: Pivotal Research Group.

Wieser, B. (2014c). Deathwatch: Agency Edition. Madison and Wall Street (September 12). New York: Pivotal Research Group.

Williamson, O. E. (2010). Transaction Cost Economics: The Natural Progression. American Economic Review, 100(June), 673-690. http://dx.doi.org/10.1257/aer.100.3.673

\section{Copyrights}

Copyright for this article is retained by the author(s), with first publication rights granted to the journal.

This is an open-access article distributed under the terms and conditions of the Creative Commons Attribution license (http://creativecommons.org/licenses/by/3.0/). 